\title{
Stakeholders' issues for action during the warning process and the interpretation of forecasts' uncertainties
}

\author{
L. Créton-Cazanave and C. Lutoff \\ Université Grenoble 1, PACTE UMR 5194 (CNRS, IEPG, UJF, UPMF), Grenoble, 38041, France \\ Correspondence to: L. Créton-Cazanave (lcretoncazanave@gmail.com)
}

Received: 30 January 2012 - Published in Nat. Hazards Earth Syst. Sci. Discuss.: Revised: 8 January 2013 - Accepted: 28 February 2013 - Published: 11 June 2013

\begin{abstract}
This article considers the socio-geographical approach carried out as part of the MedUp program. It presents a study of the ways that the French "actors" manage forecast uncertainties during a flash flood warning process. In order to better understand the role of forecasts' uncertainties in decision making, we focused on the actions people took and how what they say explains their actions. The practices of actors involved in warnings for the Vidourle watershed (Gard, France), in particular, are analyzed using a practice-based approach. A set of categories of the "actors" was developed based on their descriptions of the problems they faced during the flash flood warning, independent of their socioprofessional status and position in the warning chain. Five actor profiles result from this: Translators, Managers, Committed, Navigators and Vulnerable. For each profile, specific action contexts are defined, determining how each deals with uncertainty.
\end{abstract}

\section{Introduction}

With the emergence of issues regarding climate change, uncertainty in meteorological forecasting became a key topic in several domains. For hydro-meteorologists, the issue is quantifying uncertainties and their propagation in hydrological models and forecasts (Rossa et al., 2010). Another question social scientists face regards how to communicate uncertainties to users (Morss et al., 2008; Demeritt et al., 2010) and the impact of uncertain knowledge transfer on decision making and policies with regard to climate change, now and in the future (Wynne, 1992; Shackley and Wynne, 1996; Adger et al., 2005).
The MedUp program, which primarily focuses on the propagation of uncertainty in hydro-meteorological forecasting models, likewise allowed us to characterize actors' practices while managing the warning process and specifically to study their behaviors related to the forecasts' uncertainties. Considering the many actors involved in the whole warning process, this paper focuses on an observation of actors' actual practices, and how they consider uncertainty in their decision making and actions during potential flash flood situations.

Section 1 is a review of the literature concerning the question of uncertainty in decision making and, more specifically, in flood scenarios. Section 2 presents the methodology used to observe actors' practices during a warning process, the case study, the sample and the data collected. Then, Sect. 3 shares the results of the analysis and the profiles that correspond to the different actors. It also explores the role of the aforementioned uncertainty in the warning process. Finally, Sect. 4 takes a broader look at the contributions and limits of this approach, as they relate to uncertainty in the field of risk management.

\section{Uncertainty and action: literature review}

This section explores the existing literature on decision making, action procedures and the role of uncertainty in such scenarios. It likewise aims to define the concepts used in the paper, particularly the notion of warning process.

\subsection{Uncertainty and decision making}

In the social sciences, several authors have approached the question of uncertainty and decision making by focusing on specific hydro-meteorological phenomena, basing their 
investigations on flood risk management (e.g. Downton et al., 2005; Demeritt et al., 2007; Morss et al., 2008; Frick and Hegg, 2011). Their aim was to better understand how decision makers manage uncertainty in different situations: for instance, in predicting flood risk (Downton et al., 2005), in communicating everyday weather forecasts (Morss et al., 2008) and within the warning and alert chain (Frick and Hegg, 2011). They all showed that decision makers prefer detailed information about uncertainty, as it allows them to weight various alternatives (Downton et al., 2005, p.143) or because they could make their own assessment of the situation (Frick and Hegg, 2011, p.302). Overall, they all found that decision makers prefer having all the information available, including uncertainty estimation, which allows them to have their own interpretation of the situation rather than to follow particular recommendations. Their research findings show that decision makers need information about uncertainty to help them in the process of decisions and actions to take, but how precisely do they use the uncertainty information?

In most of the cases (except Morss et al., 2008), the people interviewed were rather high-up in the decision-making process. They tended to be administrative officers, flood managers and civil protection managers. Do these people have the same information needs as forecasters? Who decides which information to give to whom? Do people living in or near the floodplain have different information needs? How do they decide to evacuate or to stay?

The earlier studies are usually based on the hypothesis of a gap between decision makers' needs and the scientific information available. But what exactly is known about decision makers' needs along the decision making' chain in these different situations? Do they all, and always, deal in the same way with forecasts and probabilities and the inherent uncertainty of this kind of information (Morss et al., 2008)?

Following the spirit of situated action theory (e.g. Conein and Jacopin, 1994; Quéré, 1997; De Fornel and Quéré, 1999), we know that information cannot be interpreted and integrated without a clear understanding of the action context. What do we know about the different action contexts of the decision makers in question here? Handmer and Proudley (2007) showed that while much is known about how people perceive probabilities and frequencies, less is known about how this knowledge is used when making decisions and leading action in emergency situations.

In this paper we address the action processes linked with flash flood warnings as a first question, and then highlight the role of uncertainty in these action contexts.

Following Sorensen (2000), we already pointed to the inability of the classical approach of warning systems in understanding the whole processes of decision making and action in a real-life context (Créton-Cazanave, 2009). In view of the above, the MedUp program provided an opportunity to test an alternative approach that focuses on the warning process rather than on the warning system (Créton-Cazanave et al., 2009).

\subsection{Defining the warning process and practice-based approach}

Going beyond the traditional approach of warning as a communication issue (Créton-Cazanave, 2010a), Chateauraynaud and Torny (1999) propose an original approach to warning as a "dynamic process that is generative of social and technical configurations" and that requires a very concrete engagement of actors into the world through their practices. For the authors, warnings are "not the product of a preestablished system but contributes to continuously define the system in a real-life context"; each warning uses, tests, reinforces and reconfigures the system of which it is a part. The notion of process has already been considered in several works on flood warnings (Drabek, 1999; Mileti, 1995), but only with regard to the reception of/reaction to warnings by the population (warning responses). Mucchielli's (1998) proposal, combined with AFNOR's definition, allows us to go beyond the question of response in order to define warning as the socio-technical process by which the reality of a given situation is taken into consideration in order to establish its meaning, so as to constitute and coordinate action in a context of assumed danger (Créton-Cazanave, 2010b).

Therefore, warnings are less an issue of system or signal reception than an issue of action in context (e.g. Thévenot, 2006). Thus, we must look at the actual practices that allow actors to carry out warning processes. We must understand the implications of the situation, and how it affects and directs the actions people take.

To this end, we use the French Pragmatic Sociology (Nachi, 2006), that is related to so-called Practice-Based studies, and enhance practice as an empirical object as well as an epistemology. In this approach, the concept of practice relies on three dimensions (Corradi et al., 2010):

1. the set of interconnected activities that, if socially recognized as a way of ordering, stabilize collective action and the common orientation;

2. the sense-making process that supports the accountability of a shared way of doing things and which allows for the continuous negotiation (ethical and aesthetic) of the meanings of a practice by its practitioners;

3. the social effects generated by a practice in connection with other social practices. This is the dimension of the reproduction of practice that answers the question as to what purpose the practice serves.

We can see that this is really consistent with our definition of the warning process, and the approach leads us to a study of warning-as-practice. Thus, we focused our observations on "what people do, what their work is like, and what 
effort it takes to problem solve their respective combinations of objects and ends" (Carlile, 2002) during a warning.

The question of uncertainty arises in such a situation: what are its roles and implications on the practices of actors involved in the warning process? Such an approach requires using methods that will allow us to consider the entire process. We take into account all the actors involved, from the forecasters to the risk managers and the riverside residents. In investigating the warning process, we study the supposed gap between needs and available information, and we assess if and how uncertainty is taken into account in this process.

\section{Research design, data and methods}

This section clarifies the methodological aspects of our study and presents the case study and data used to carry out the analysis.

\subsection{Observing the concrete practices of actors}

Based on the earlier research cited above, we observe the entire warning process, as it is carried out by the different actors involved, in practice and in context. We used the same interview grid for all the actors we encountered, so as to not introduce any a priori distinction between them. It was essential to consider all actors equally, without assuming any differential of rationality, scientificity or issues with regard to interaction between them. This symmetry (Bloor, 1976) was maintained throughout the analysis.

Our protocol was based on semi-directive interviews as defined by Huntington, with open and free answers, and interventions for helping interviewees develop specific points (Huntington, 1998). The interviews focused on two dimensions: 1) actors' usual practices, i.e. what they usually do (and how) when a flood occurs, and 2) a reconstruction of their specific warning activities during the major 2005 flood event in the Gard region. The interview guide included two key questions:

1. Can you describe how you carry out a flood warning?

2. Can you tell me what happened in 2005 ?

With this second question, the goal was to have them explain what took place during this event in particular, with special attention to time markers. This phase of the interview allowed us to introduce more thickness (Geertz, 1973) in the description of the 2005 process, taking into account not only the facts, but also the meaning attached to them by the actors, as well as the practices that produce these facts (i.e. the triggers of action from which the facts result).

Close attention was paid to the specific skills and the relationships involved both in normal activities and during the warning process.

Note that in this interview grid, uncertainty was not the focus of our investigation. It was not directly mentioned. Un- derstanding the warning process based on actors's practices and the issue of action in general meant not focusing on the issues faced by researchers. On the contrary, we attempted to describe the modalities of actors' actions as they understand and execute them, and then we analyzed the role of uncertainty.

\subsection{Case study: a flash flood warning process}

For this study, and in accordance with MedUp project members, we focused our analyses on the Vidourle watershed (Gard department, Southern France) (Fig. 1), which presents a number of interesting characteristics:

- A relatively short coastal river $(85 \mathrm{~km})$, this site allowed us to observe all the geographical configurations from its source in the Cevenol mountains (where the river freely evolves along the mountain slopes), through the Petite Camargue in the Gard plain (which is currently in the process of re-urbanizing (Balk, 1945; Bauer and Roux, 1976)), to its outlet at the seaside town of Grau du Roi. The characteristics of the relationships the different residents have with the river likewise differ, depending, in particular, on whether their area is diked or not.

- The Vidourlades are an old, recurring phenomenon of violent flash floods in the Vidourle catchment, wellknown within the entire Gard department. From this specificity results, all along the Vidourle river, a gradual development of a veritable culture based on these phenomena and the river's development, as well as abundant regional and historical literature (e.g. Gaussen, 1968; Coeur, 2007). As a border river between two French departments (the Gard and the Hérault), this site also allowed us to consider some institutional aspects of the warning process.

- All types of actors involved in warning processes are present in this area, from State monitoring (SPC Grand Delta) to private contractors who propose their decision making aid services to towns when floods may occur.

Finally, this area also has a reputation for efficiency in terms of water crisis management, and is therefore an interesting choice for this reason. While quantifying the efficiency of warnings is difficult (Carsell et al., 2004), the warnings that people in the Vidourle basin have seen have been more or less effective. At least this is what numerous actors in civil protection at the department-wide level say, especially regarding the complexity of issues to be resolved and the number of small warnings they must deal with each year. The Vidourle Plan was validated as a National Pilot Project in 2003. This site therefore seemed especially interesting in terms of identifying and understanding what factors lead to the successfully carrying out of warnings and how uncertainty may be handled. 


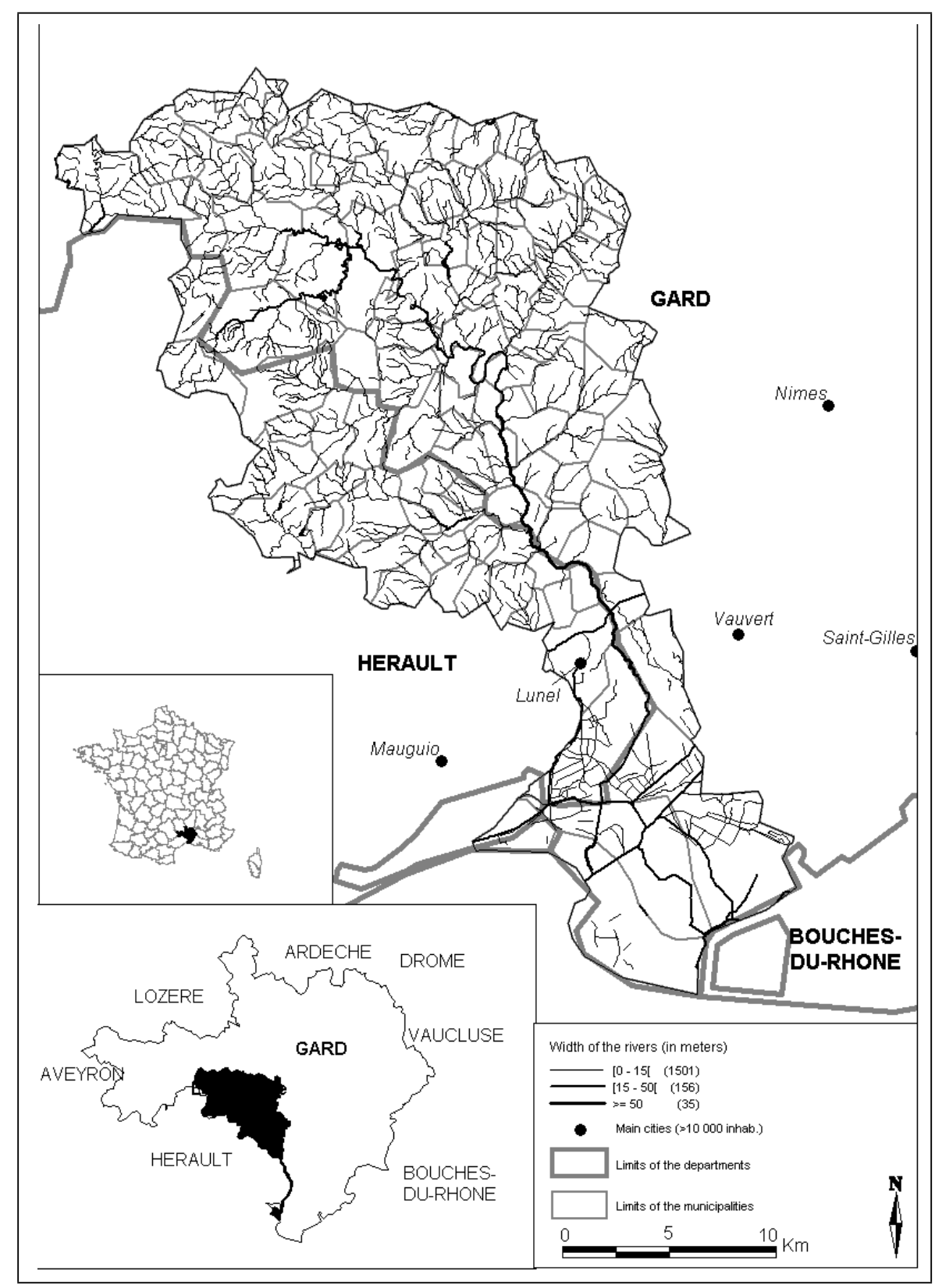

Fig. 1. Vidourle watershed.

The choice of the Vidourle basin allowed us to determine the starting point for the warning process we wanted to observe, and thus to identify, in a bottom-up manner, the actors involved in this warning process.

\subsection{Specificity of the sample}

The sample of individuals questioned was defined based on the aforementioned need to consider the warning process in all its dimensions. Specifically, this meant identifying all the actors concretely involved in the process, officially or otherwise. Gray literature concerning the official organization of warnings according to the State and post-event investigation reports served as our basis for identifying the initial set of actors who intervened at different times during the warning process and on different spatial levels:

- For weather forecasting : The National Center of Forecasts (Centre National de Prévision, CNP) in Toulouse, The Inter-regional Meteorological Center (Centre Météorologique Inter-régional, CMIR) in Aixen-Provence and The Departmental Meteorological Center (Centre Départemental de Météorologie, CDM) in Nimes; 
- for flood advisory : The Hydro-meteorological Service Center and Flood Prevention Support (Service Central d'Hydrométéorologie et d'Appui à la Prévention des Inondations, SCHAPI) in Toulouse and The Flood Forecasting Service in Nimes (Service de Prévision des Crues Grand Delta, SPC-GD);

- for handling the event and informing the public at the department-wide level: The Inter-ministerial Service for Defence and Civil Protection (Service Interministériel de Défense et de Protection Civile, SIDPC) in Nimes, and the radio station "Radio France Bleu Gard/Lozère";

- for handling the event at the local level : mayors, who are responsible for warning their districts and a private company specialized in aiding decision making for the induction of town-wide protection plans (Plans Communaux de Sauvegarde).

On this basis, we allowed the actors to define themselves amongst themselves throughout the course of our fieldwork. With the snowball effect, we saw individuals who are usually invisible suddenly come to the fore. This was the case for the floods observers (observateurs de crues), who were formerly employed by the State's departmental services to control the Vidourle's water levels under normal circumstances, monitor the river in case of flooding and regularly apprise departmental authorities and local actors (mayors, the population, etc.) of the situation. We added to the list dam monitors, country policemen, local experts (often considered the mayor's eyes on the ground), certain farmers, elected representatives or inhabitants recognized for their knowledge of the river, departmental authorities (the Conseil Général of the Gard department), Météo France's media service, and waterways authorities (Voies Navigables de France), etc.

Our sample thus considers all the actors seen as involved in practice during hydro-meteorological warnings for the Vidourle watershed. The sample is characterized by its heterogeneity in terms of actors and the range of spatial (town, watershed, departmental, regional and national levels) and temporal scales (from ten minutes to a whole week) involved.

\subsection{Data and analysis}

The data were collected from October 2007 to September 2008. During 11 weeks in the field, we:

- collected 93 semi-directive interviews with actors;

- observed in situ the CNP, SCHAPI and emergency response units;

- collected 3 notebooks from town halls, 4 post-event reports on the 2005 event (from different authorities), and numerous technical and historical documents on the Vidourle.
We spent a great deal of time visiting the places and areas, and this travel time provided us with indispensable acculturation, allowing us to get to know the area and improving the quality of the interactions during interviews.

The interviews were transcribed, word for word, before the analysis, which was conducted in two phases. First, we scanned the 72 interviews to identify the occurrences of the word "uncertainty", we counted them and analyzed its distribution (see Sect. 3.1). Next, we looked at the content of these interviews, so as to better grasp how actors expressed the problem of uncertainty, linked to forecasting tools, in their specific context of practice. This second phase allowed us to see how the problem of uncertainty is expressed by the actors of the warning process.

To observe and analyze all the actors on the same grid, the analysis was framed both by a longitudinal reading of each actor's practices, as well as a transversal and comparative reading for all the actors involved in the warning process. It was then possible to code the interviews for each actor in a qualitative database, from which we can make statistical analyses. Multi-factor statistical analyses on this data base (principal component analysis (PCA) and ascendant hierarchical classification (HAC)) enabled us to establish profiles of actors involved in the warning process, characterized by their practices and the role of uncertainties (for more details on the statistical analysis, see (CrétonCazanave, 2010b)).

Note that these profiles of actors must be understood as ideal types. They are an abstract model that, when used as a standard of comparison, enables us to see aspects of the real world in a clearer, more systematic way. It is a constructed ideal used to approximate reality by selecting and accentuating certain elements (Weber, 1965). These profiles should then not be understood as a description of some precise individual, whose practices may indeed fall under different profiles.

\section{Results}

It makes sense to expose first our findings about the use of the word "uncertainty" by the actors when they talk about their practices and issues for action during a warning process. It makes it even clearer that uncertainty can not be understood prior to the action process.

\subsection{Uncertainty: not such a big deal?}

From the scanning of semi-directive interviews, several important quantitative findings came to light:

The word uncertainty only appeared in 12 of the 72 interviews scanned, and of those 12 , only 8 actors used the word spontaneously (i.e. without being prompted by the interviewer). 
If we look more closely at these 12 interviews, we find 55 occurrences of the word uncertainty. Considering that these semi-directive interviews total 357 pages, or approximately 183500 words, we can assume that uncertainty is mentioned roughly once every six pages. If we take out those occurrences linked to the interviewer, that leaves 28 occurrences of the word, as said by the interviewee, approximately once every 13 pages.

When we look more closely when interviewees evoked uncertainty, we find that forecasters spoke most openly about this issue (Météo France, SCHAPI, SPC, and others). In refining our analysis of these particular interviews, we nonetheless noted that uncertainty, as thought by our geoscientist colleagues in the MedUp program (especially in a quantitative way), appeared very infrequently.

However, numerous problems linked to forecasting tools were brought up, which gives us insight into the form of the problem for actors involved in warning process, even if they are not expressed explicitly as uncertainty.

\subsection{Issues for actors: uncertainty or discrepancy?}

The practice-based study of warning demands that we trust actors and take their discourse and practices as a basis for redefining what can be considered uncertainty, in terms of issues with regard to their action. As a result of the classification performed on the built qualitative database, we propose characterizing the actor profiles and defining uncertainty for each of them.

\subsubsection{Profile 1 - the Translators}

Actors who fall into the Profile 1 category share skills in terms of forecasting phenomena (but without necessarily being an official forecaster) and the fact that they were outside the watershed in this case. Translators are experts when it comes to interpreting phenomena and models. They are also extremely conscious of the problems of interpreting encountered by non-experts vis-à-vis phenomena and forecasting tools and products. They are greatly concerned with the problems of interpretation and comprehension between their field of expertise (weather forecasting, weather phenomena) and that of non-experts, and thus position themselves at the interface between the forecasting world and that of nonforecasters, with the job of linking the two. In the warning process, Translators position themselves more or less upstream (interpreting the environment), distinguishing themselves by their desire to produce meaning rather than data.

The problem with regard to action mentioned by Translators is the non-identity between the results of models and the reality of the environment they are supposed to describe. This problem results as much from the inherent limits of models as from the question of scale: a mayor cannot consider a regional weather forecast as viable to the reality of his immediate environment. For Translators, this non-identity, or dis- crepancy between information and the reality in which actors must act, is not so much a problem for them as it is for others. In the warning process, Translators' role is to facilitate the adapting of information resulting from tools to a specific context for different actors to use. These important skills in terms of tools allow them to easily play with information and its limits. Potential discrepancies in no way stop them from doing their job, but can, however, pose a problem for other actors. This explains their position at the interface between forecasting and the risk management.

\subsubsection{Profile 2 - the Managers}

The Profile 2 is characterized first and foremost by its intermediate position, one that we find almost anywhere in the warning process, from the forecaster to the rural policeman. Their uniqueness has less to do with required skills than personal and professional posture. Managers are characterized above all by the importance they give to procedure, regardless of their position in it. We could consider them as ideal actors in the warning system. Their concerns are extremely targeted, depending on their job. While they are extremely invested in their incumbent duties, they also know the limits and do not necessarily try to go outside of them.

The Managers are characterized by their implication in the forward planning typical of warning systems. This forward planning takes the form of different maps, procedures and regulations that organize the distribution of tasks among the actors involved in the warning process. In this context, Managers are characterized by the great attention they pay to these procedures, as well as how they adhere to them; they take responsibility for the duties assigned to them by the procedure, but not more. What counts is not their individuality but the continuity of the post. Managers can be described as individuals who carry out and respect procedures.

What seems to worry Managers most is also the discrepancy between information about the environment and the reality. The question for them is more direct and more concrete, however: how can they base their action on information that is not valid for the environment targeted by their action? The problem raised by Managers has in fact little to do with technical uncertainty. It results rather from the choices (political and scientific) that have led to the production of information at certain scales or for certain phenomena; information that does not serve necessarily as a relevant basis for their action. Their position with regard to action is technocratic, procedural and not really geographically rooted, requiring specific scientific information upon which to base their actions.

In this context, the discrepancies between available information and the reality targeted by the action become extremely problematic because they correspond to the failure of the primary resource of action. Managers, unlike Translators, are therefore in no way able to use information that proves not valid for their own context. These discrepancies may then seriously endanger the carrying out of action. Managers are 
the ones who most often question forecasts, not so much in terms of its quality (or the degree of uncertainty) as it relevancy (the forecast does not concern what they are interested in). Therefore, they often call upon Translators, or depend greatly on the procedures and predetermined thresholds so as to justify their actions.

\subsubsection{Profile 3 - the Committed}

The 3rd profile is centered, more so than any other, around the human actors involved in the warning process. The Committed are those actors who intervene directly in the watershed and department. They are characterized by their attention to the issue of floods and flooding, and are universally recognized for their background, skills and experience in these subjects. In fact, the Committed can be seen as Managers who go above and beyond the call of procedure.

Thus, this profile is quite remarkable due to the importance of its intersubjective relationships with other actors, and by the autonomy it demands with regard to technical and procedural systems and prescriptive authorities. More than any other profile, the Committed demonstrate a strong sense of belonging to the group responsible for warning processes and the resulting need to position itself with regard to its actors. This type of actor positions itself in close proximity to the terrain and as a critical user of all the information on the environment (forecasts most notably) produced by these other actors. Finally, the Committed trust other warning actors to produce and provide them with information on the environment, which they then confirm through their own sensitive and personal experience. These actors are characterized by (and recognized for) their personal investment in the warning process, which can be compared to what is usually called vocation in sociology (Weber, 1919). The Committed therefore see the problem of floods from the point of view of vulnerability rather than the phenomenon.

For the Committed, the discrepancy between information originating from models and the reality of their environment is source data that gets integrated from the very planning stages of the action. Less vindictive than Managers, they consider this discrepancy as unavoidable and thus tend to increase the number of their sources of information (to not depend on forecasts alone) in order to effectively base their actions in a given context. They can admit to these discrepancies and the fact that information and forecasts are not entirely valid for real life, as they are able to rely on other input to understand this reality and as this does not stop them from taking action. Most notably, they can rely on Translators to complement or mitigate the limitations of forecasts.

\subsubsection{Profile 4 - the Navigators}

Actors in the Profile 4 have in common their scientific expertise in terms of forecasting, the fact that they are outside the watershed and that they tend to act at the regional and national levels. They are also characterized by their intermediate position between two professions: forecaster and journalist, researcher and operational.

Remarkably, as compared to other profiles, Navigators demonstrate an ability to take great critical distance to objects in the warning process (tools, supports and data), and can be seen as reflexive specialists as well as operational specialists. They are characterized by their great attention to the compatibility between actors' environments of action. They seem most concerned with creating good supports for action in the warning process. Compared to Translators, who also evoked the difficulties of translating between environments and finding themselves at the interface, striving to translate toward other environments, Navigators are comfortable in several environments and act as heralds from one to another, but without attempting to create bridges or points of translation between the two. We can say that they tend to make themselves unavoidable in some situations.

Navigators likewise brought up the issue of discrepancy, and consider as a key problem the fact that information from forecasts is not valid to reality. They link this to both the limitations of models and the problem of scales, and consider that this is one of the basic problems in the warning process, one that has an unquestionable impact on the quality of warnings. As with Translators, this is not a problem for them, as their knowledge of models and of the field allows them to extract the information they need. On the other hand, Navigators are worried about the impact these discrepancies have on the rest of the warning process.

\subsubsection{Profile 5 - the Vulnerable}

The 5th profile essentially includes inhabitants of riverside towns, who typically are not seen as actors in the warning process. The Vulnerable are above all characterized by the relatively few and extremely localized means of action they have. The problem for Vidourle riverside residents is that of flooding and the likelihood of water invading their private environments with a devastating impact. This physical proximity to the river, however, allows for easy access to the river and, as such, continuous monitoring. Their social and geographical proximity to local actors results in great trust in the efficiency of their social networks for warnings.

This profile is therefore structured by a very practical vision of the problem: Is the Vidourle going to stay in its own bed or end up in mine? Such is the direct constraint the river imposes on these individuals and with regards to which they are rather unfortunate: one cannot stop the water from coming; one can only limit the damages.

This is the only profile that is not institutionally involved in the warning process. Its role is that of the final recipient and judge of the warning process. The Vulnerable in this way correspond perfectly to the classic conception of the population. Nonetheless, we might ask ourselves to what extent this 
wait-and-see position should be seen as a justification for the classic approach to warning, or as a consequence of it.

The description of actor profiles and their relationship to uncertainty allows us to better understand what is at stake during the warning process. We will now capsulate this information to offer a more in-depth analysis of the action contexts and how uncertainty is dealt with.

\section{Synthesis and discussion}

The table below (Table 1) provides a summary of the information described above and a more general view of the relationship between action context, practices and problems of uncertainty. Note that during the interviews, some of the actors made mention of solutions to deal with the problems we identified. A more in-depth analysis of these strategies is currently underway.

We deliberately organized the actor profiles to highlight their similarities and differences. We see that Translators and Navigators are quite close in terms of how they handle situations of crisis and uncertainty. They have technical skills that allow them to grasp the meaning of uncertainty in forecasting tools, without it hampering their action. They are aware of what really poses a problem for actors involved in the warning process: the discrepancy between forecasts (output from models) at a specific scale and the scale of action in the field (i.e. a watershed, for instance). In practice, they are both involved in interpreting or adapting the information for facilitating local action.

This puts both of these sets of actors in a position of strength in the warning process. However, the main difference between these two actor profiles is that Translators, whose action is close to the field, try to lessen the discrepancies, while Navigators, who are offsite, have no real grasp on local action and maintain a non-specialized position in the warning process.

We can also draw similarities between Managers and the Committed, who can position themselves anywhere in the warning chain. Both are perfectly familiar with the predefined procedures for handling a warning. For them, uncertainty results in this qualitative discrepancy between forecasting and the field, especially in terms of scales of reference. This discrepancy, however, does not have the same impact on their practices. While they completely immobilize the action of Managers, which is rooted in procedure, the Committed, strengthened by their experience, see it as source of data, adapt to it and seek solutions to act in spite of it.

The Vulnerable distinguish themselves by their wait-andsee attitude with regard to the warning process with, in practice, a monitoring of the situation. We must be careful to avoid any confusion between the Vulnerable and the population at-risk. While proximity to the river (i.e. danger) is a key characteristic for this profile, all riverside residents cannot be defined as Vulnerable in the sense that we mean here: some, by their skills and/or experience, can be defined as Committed or Translators in profile.

If we focus on action contexts and relationships to uncertainty, we can make the following observations:

- Technical and scientific knowledge with regard to forecasts makes it possible to deal with the uncertainty inherent to them. As several authors have underlined (see Sect. 1.1), the accuracy of the data as regards this uncertainty then serves as additional information that is in no way harmful to action;

- Clear awareness of the problems encountered by field actors in using forecast data (and the issue of scale more specifically), coupled with a technical knowledge of models, grants certain actors a kind of power in the warning process;

- Rooting in pre-established procedure and legitimization of action exclusively with regards to a plan weakens action. Uncertainty (regardless of the form) then becomes an impediment;

- A wait-and-see attitude (to which the preceding instance can also be added) fosters a way of handling risks that is more or less curative. As early action entirely depends on other actors (or procedures), the actors concerned ultimately find themselves in the critical situation of crisis management, in which there is no room for uncertainty (because the danger is manifest);

- Experience obviously plays an essential role. Coupled with voluntary commitment closer to the action and terrain, it is indispensable for finding solutions that are suited to circumstances that are inherently uncertain.

If we go back to the questions and hypotheses raised in the literature review, the analysis conducted here offers several clues.

The first concerns actors' expectations in terms of forecasting. Several authors say that actors responsible for managing floods demand detailed information, including details about uncertainty. This information seems indispensable for them to be able to assess the situation by themselves and evaluate the possible alternatives. The analysis conducted here shows that this holds true for actors who possess some form of expertise and the scientific/technical knowledge required to interpret this information and extract from it that which will help them act. Other actors are, on the contrary, in need of translation of this information (i.e. an adaptation for their specific action context). Some private companies (currently appearing in France) have understood this and are taking on the role of translator at the interface between forecasters and local actors.

Note that our approach can introduce a bias. We chose not to focus the interviews on uncertainties, assuming that the issue would indirectly emerge through the description of practices. But this option could have led some actors to ignore 
Table 1. Synthesis of the relationships between actor profiles, action context and uncertainty.

\begin{tabular}{|c|c|c|c|}
\hline Profiles & Action context & $\begin{array}{l}\text { Practices in the warning } \\
\text { process }\end{array}$ & Problem of uncertainty \\
\hline The Translator & $\begin{array}{l}\text { - Experts in interpreting phenomena } \\
\text { - Technical knowledge of models } \\
\text { - Concerned with the difficulties of } \\
\text { other actors }\end{array}$ & $\begin{array}{l}\text { - Interprets outputs of } \\
\text { modelisation according to } \\
\text { local and operational } \\
\text { issues } \\
\text { - Translates forecasts for } \\
\text { local and operational } \\
\text { actors }\end{array}$ & $\begin{array}{l}\text { - No particular problems as regards } \\
\text { their own action } \\
\text { - Discrepancies between the output } \\
\text { of models and the reality of the } \\
\text { environment in question } \\
\text { (identified for the other actors) }\end{array}$ \\
\hline The Navigator & $\begin{array}{l}\text { - Scientific expertise in forecasting } \\
\text { (technical knowledge of tools) } \\
\text { - Critical attitude to tools and data from } \\
\text { action processes (reflexive position) } \\
\text { - Offsite (action at the regional or } \\
\text { national level) } \\
\text { - Sensitive to the problems of other } \\
\text { actors without being in contact with } \\
\text { them }\end{array}$ & $\begin{array}{l}\text { - Creates and improves } \\
\text { media for information } \\
\text { - Tries to address and } \\
\text { diminish the discrepancy } \\
\text { between models/real } \\
\text { situation, in long term. }\end{array}$ & $\begin{array}{l}\text { - No particular problems as regards } \\
\text { their own action } \\
\text { - The discrepancy between the output } \\
\text { of models and the reality of the } \\
\text { situation identified as the main } \\
\text { problem in the warning process }\end{array}$ \\
\hline The Manager & $\begin{array}{l}\text { - Can be found anywhere in the } \\
\text { warning chain } \\
\text { - Importance given to procedure } \\
\text { (prescription) and the legitimacy of a } \\
\text { given action }\end{array}$ & $\begin{array}{l}\text { - Applies procedures } \\
\text { and follows the rules, } \\
\text { whatever they are } \\
\text { - Expects the others will do } \\
\text { the same }\end{array}$ & $\begin{array}{l}\text { - The discrepancy between } \\
\text { information about the environment } \\
\text { (output from models) and the real } \\
\text { environment } \\
\text { - Uncertainty weakens the very basis } \\
\text { of action (procedure) }\end{array}$ \\
\hline The Committed & $\begin{array}{l}\text { - Relationship with other actors } \\
\text { fundamental for action } \\
\text { - Close to the field: locally recognized } \\
\text { for their experience } \\
\text { - Committed to action (vocation) } \\
\text { - Profile comparable to that of } \\
\text { Managers, but with the ability to step } \\
\text { outside of procedure }\end{array}$ & $\begin{array}{l}\text { - Interprets and adapts the } \\
\text { procedure according to } \\
\text { the local situation and } \\
\text { constraints } \\
\text { - Acts beyond the } \\
\text { procedure when it seems } \\
\text { relevant }\end{array}$ & $\begin{array}{l}\text { - Uncertainty = discrepancy between } \\
\text { the forecasted and the real } \\
\text { - Acts as source data for action. } \\
\text { Searches for alternative solutions }\end{array}$ \\
\hline The Vulnerable & $\begin{array}{l}\text { - Physical proximity to the river } \\
\text { - Strong sense of belonging to different } \\
\text { networks (neighborhood, friends, } \\
\text { colleagues, etc.) } \\
\text { - Standby recipient of warnings }\end{array}$ & $\begin{array}{l}\text { - Monitors the local } \\
\text { situation (waterflow) } \\
\text { - Awaits official } \\
\text { instructions } \\
\text { - Shares information within } \\
\text { his networks and takes } \\
\text { advice from local experts }\end{array}$ & $\begin{array}{l}\text { - Did not mention uncertainty in their } \\
\text { discourse } \\
\text { - Problem = will there be overflow? } \\
\text { If so, how to limit the damages? } \\
\text { - No uncertainty, as overflowing can } \\
\text { be established visually }\end{array}$ \\
\hline
\end{tabular}

the problem of uncertainties, as external to the specific topic of the interviews, even if the interviewer encouraged them to explore this question.

A second question concerns accurate definition of the needs of forecasts users in the warning process. What we have learned from our analysis is that these needs differ from one actor to another and are directly linked to their problems of action. The Committed do not have the same needs in terms of information in order to act as Managers and Navigators do. And yet, these problems of action do not only depend on their socio-professional status : depending on how they perceive their action, one meteorological forecaster can be a Manager and another forecaster can be a Committed, even though they belong to the same institution.

Knowing their duties and their role in the warning chain alone is not sufficient; it is crucial to understand their problems and action contexts in order to define their needs and assess the impact of uncertainty on their actions. The proposed approach aims to progress on this way. However, the definition of these categories of actors is based here on one specific case study. It has to be tested in other contexts for assessing its robustness. 


\section{Conclusions}

Upon concluding this analysis, we find that uncertainty as thought of and explored within the framework of the MedUp program (like the imprecision and margins of error inherent to the models) seldom comes up in the discourses of warning actors. It only seems a matter of concern to the actors directly involved in forecasting.

However, another form of uncertainty, not necessarily identified as such by actors, appears as a key problem when it comes time to alert: a discrepancy between the information conveyed (forecasts) and the reality of the environment in question, especially in terms of scale (i.e. the forecast is not necessarily valid for the environment in which each actor intervenes).

The practice-based approach allowed us to better characterize this form of uncertainty and to better understand its impact on the decision making process in warning situation. We showed that in some cases, it can lead to inaction, particularly when the procedure is the single context of action. In other situations, uncertainty leads to an interpretation of the situation and to an adaptation for allowing the action.

As shown in previous works, there is a gap between the information provided by forecasters and the users of this information. However, this does not affect the degree of uncertainty as much as the harmonizing of information and the action context in question. The real problem for warnings is not knowing whether a forecast is 92 or $95 \%$ reliable. What can be a constraint for action to issue a warning instead concerns the scale of the forecast, and the fact that this scale does not necessarily correspond to that of the action. This is particularly true with regard to flash floods, a phenomenon that shows great variability depending on the scales considered (Creutin et al., 2011). Thus, issuing a level orange alert at the department-wide scale in Gard is not sufficient for actors who must direct and base their action(s) in the Vidourle watershed or any of the towns therein.

A second important lesson stemming from this work has to do with the actors themselves. Thanks to this practicebased study of the warning process, we highlight categories of actors that greatly differ from those typically predefined in studies on warning systems. Translators, Managers and the Vulnerable, for instance, correspond to actors that could belong to the building trade and very diverse social statuses. A riverside resident can either be a Translator or Committed, based on his/her action, or Vulnerable. The methodological option we used allowed us to break down predefined actor categories and rebuild profiles based on problems of action and actors' concrete practices, regardless of their position in the warning chain or their socio-professional status.

By outlining the practical dimension of the warning process (beyond its communicational aspects), by taking into account concrete actors' practices, and by offering a comparison of the all the actors involved, this kind of practice-based study enabled us to gain new perspective on the warning pro- cess and to better understand what is at stake in the hours that precede an extreme weather event.

This method has been tested on a single case study, with regard to flash flood warnings. However, it is currently being applied to other systems of actors and other processes: information regarding road conditions during unstable hydrometeorological episodes, as part of the ANR PReDiFlood project for instance, or landslide monitoring and management as part of the ANR SLAMS.

Acknowledgements. This work was partly funded by the Agence Nationale pour la Recherche (ANR) through the program MedUp, and by the Région Rhône-Alpes, through a doctoral scholarship. This work would have not been possible without the interest and the goodwill of all the actors we met. We appreciate their support. Finally, we wish to thank the three reviewers, whose constructive comments helped us to improve significantly this paper. A special thanks to Eve Gruntfest for the English proofreading.

Edited by: V. Ducrocq

Reviewed by: O. Petrucci, D. Demeritt, and one anonymous referee

\section{References}

Adger, W. N., Arnell, N. W., and Tompkins, E. L.: Successful adaptation to climate change across scales, Global Environ. Chang. Part A, 15, 77-86, 2005.

Balk, H.: Rurbanization of Worcester's Environs, Economic Geogr., 21, 104-116, 1945.

Bauer, G. and Roux, J.-M.: La Rurbanisation ou la Ville Eparpillée, Edition du Seuil, Paris, 192 pp., 1976.

Bloor, D.: Knowledge and social imagery, The University of Chicago Press, 1991 edn., 1976.

Carlile, P.: A pragmatic view of knowledge and boundaries: Boundary objects in new product development, Organization Science, 13, 4, 442-455, July-August, 2002.

Carsell, K. M., Pingel, N. D., and Ford, D. T.: Quantifying the Benefit of a Flood Warning System, Nat. Hazards Rev., 5, 131-140, 2004.

Chateauraynaud, F. and Torny, D.: Les sombres précurseurs: une sociologie pragmatique de l'alerte et du risque, EHESS, Paris, 476 pp., 1999.

Coeur, D.: Etude Historique de l'aménagement de la basse vallée du Vidourle., Tech. rep., Syndicat Interdépartemental d'Améngement du Vidourle (SIAV), 16 pp., 2007.

Conein, B. and Jacopin, E.: Action située et cognition, le savoir en place, Sociologie du travail, 36, 475-500, 1994.

Corradi, G., Gherardi, S., and Verzelloni, L.: Through the practice lens: Where is the bandwagon of practice-based studies heading?, Manage. Learn., 41, 265-283, 2010.

Créton-Cazanave, L.: Warning ! The use of meteorological information during a flash flood warning process, Adv. Sci. Res., 3, 99-103, 2009.

Créton-Cazanave, L.: Processus d'alerte et communication : quelles distances à franchir ?, in: Risques et communication : une mise en perspective. Actes de l'atelier RISCO, 2008-2009, edited by: Chaskiel, P., 187-224, MSHS Toulouse, 2010a. 
Créton-Cazanave, L.: Penser l'alerte par les distances. Entre planification et émancipation, l'exemple du processus d'alerte aux crues rapides sur le bassin versant du Vidourle, Ph.D. thesis, Institut de Géographie Alpine, Université de Grenoble, 2010b.

Créton-Cazanave, L., Lutoff, C., and Soubeyran, O.: Alerte aux crues rapides : de l'utilité d'une nouvelle approche., in: Risques et environnement : recherches interdisciplinaires sur la vulnérabilité des sociétés, edited by: Pletier, A. and Becerra, S., chap. Vulnérabil, pp. 483-494, L'Harmattan, 2009.

Creutin, J.-D., Borga, M., Gruntfest, E., Lutoff, C., Zoccatelli, D., and Ruin, I.: A space and time framework for analyzing human anticipation of falsh-floods, J. Hydrol., 10.1016/j.jhydrol.2012.11.009, in press, 2012.

De Fornel, M. and Quéré, L.: La logique des situations : nouveaux regards sur l'écologie des activités sociales, Editions de l'Ecole des hautes études en sciences sociales, Paris, 358 pp., 1999.

Demeritt, D., Cloke, H., Pappenberger, F., Thielen, J., Bartholmes, J., and Ramos, M.: Ensemble predictions and perceptions of risk, uncertainty, and error in flood forecasting, Environ. Hazards, 7, 115-127, 2007.

Demeritt, D., Nobert, S., Cloke, H., and Pappenberger, F.: Challenges in communicating and using ensembles in operational flood forecasting, Meteorol. Appl., 17, 209-222, 2010.

Downton, M., Morss, R. E., Wilhelmi, O., Gruntfest, E., and Higgins, M.: Interactions between scientific uncertainty and flood management decisions: Two case studies in Colorado, Global Environ. Chang. Part B: Environ. Hazards, 6, 134-146, 2005.

Drabek, T. E.: Understanding Disaster Warning Responses, The Social Science Journal, 36, 515-523, 1999.

Frick, J. and Hegg, C.: Can end-users' flood management decision making be improved by information about forecast uncertainty?, Atmos. Res., 100 (2-3), 296-303, 2011.

Gaussen, I.: Sommières, promenade à travers son passé, s. n, 169 pp., 1968.

Geertz, C.: Thick description: Toward an interpretive theory of culture, in: The interpretation of cultures: selected essays, 3-30, Basic Books New York, 1973.
Handmer, J. and Proudley, B.: Communicating uncertainty via probabilities: The case of weather forecasts, Environ. Hazards, 79-87, 2007.

Huntington, H.: Observations on the utility of the semi-directive interview for documenting traditional ecological knowledge, Arctic, 51, 3, 237-242, September 1998.

Mileti, D. S.: Factors related to flood warning response, in: U.S.Italy Research Workshop on the Hydrometeorology, Impacts, and Management of Extreme Floods, 17 pp., Perugia, 1995.

Morss, R. E., Demuth, J. L., and Lazo, J. K.: Communicating uncertainty in weather forecasts: A survey of the US public, Weather Forecast., 23, 974-991, 2008.

Mucchielli, A., Corbalan, J.-A., and Ferrandez, V.: Théorie des processus de la communication, Armand Collin, Collection U Communication, 175 pp., ISBN:2-200-01882-7, 1998.

Nachi, M.: Introduction à la sociologie pragmatique: vers un nouveau "style" sociologique?, Armand Colin, Collection CursusSociologie, 223 pp., 2006.

Quéré, L.: La situation toujours négligée?, Réseaux, 15, 163-192, 1997.

Rossa, A., Liechti, K., and Zappa, M.: The COST 731 Action: A review on uncertainty propagation in advanced hydrometeorological forecast systems, Atmos. Res., 100, 150-167, 2010.

Shackley, S. and Wynne, B.: Representing uncertainty in global climate change science and policy: Boundary-ordering devices and authority, doi:10.1177/016224399602100302, Science Technology Human Values, 21, 3, 275-302, July 1996.

Sorensen, J. H.: Hazard Warning Systems: Review of 20 years of progress, Nat. Hazards Rev., 1, 119-125, 2000.

Thévenot, L.: L'action au pluriel: sociologie des régimes d'engagement, Éditions La Découverte, 311 pp., Paris, 2006.

Weber, M.: Le savant et le politique, Plon, Bibliothèque 10/18, 1959 edn., 230 pp., 1919.

Weber, M.: Essais sur la théorie de la science, Plon, 1992 edn., 537 pp., 1965.

Wynne, B.: Uncertainty and environmental learning: Reconceiving science and policy in the preventive paradigm, Global Environ. Change, 2, 111-127, 1992. 